\title{
Recent Advances in Adaptive Liquid Crystal Lenses
}

\author{
José Francisco Algorri ${ }^{1, *} \mathbb{C}$, Dimitrios C. Zografopoulos ${ }^{2}$, Virginia Urruchi ${ }^{1}$ and \\ José Manuel Sánchez-Pena ${ }^{1}$ (D) \\ 1 GDAF-UC3M, Displays and Photonics Applications Group, Department of Electronic Technology, \\ Carlos III University of Madrid, Leganés, 28911 Madrid, Spain; vurruchi@ing.uc3m.es (V.U.); \\ jmpena@ing.uc3m.es (J.M.S.-P.) \\ 2 Consiglio Nazionale delle Ricerche, Istituto per la Microelettronica e Microsistemi, 00133 Rome, Italy; \\ dimitrios.zografopoulos@artov.imm.cnr.it \\ * Correspondence: jalgorri@ing.uc3m.es; Tel.: +34-916-245-964
}

Received: 9 May 2019; Accepted: 23 May 2019; Published: 25 May 2019

\begin{abstract}
An adaptive-focus lens is a device that is capable of tuning its focal length by means of an external stimulus. Numerous techniques for the demonstration of such devices have been reported thus far. Moving beyond traditional solutions, several new approaches have been proposed in recent years based on the use of liquid crystals, which can have a great impact in emerging applications. This work focuses on the recent advances in liquid crystal lenses with diameters larger than $1 \mathrm{~mm}$. Recent demonstrations and their performance characteristics are reviewed, discussing the advantages and disadvantages of the reported technologies and identifying the challenges and future prospects in the active research field of adaptive-focus liquid crystal (LC) lenses.
\end{abstract}

Keywords: adaptive-focus lenses; liquid crystal lenses; phase modulation

\section{Introduction}

Dating back to 1888 , the physiologist F. Reinitzer and physicist O. Lehmann described the unusual characteristics of a new state of matter, liquid crystals (LCs) [1]. Since that time and up to more than 70 years later, they remained as purely a scientific curiosity. It was in 1958 when Glen Brown published an article entitled "The Mesomorphic State" in the journal Chemical Reviews [2], which reminded the scientific community of the useful LC properties which were revealed years ago by V. K. Freedericksz and V. N. Tsvetkov. Along with the pioneering work of R. Williams and subsequently, of G. H. Heilmeier [3], a revolution was triggered regarding this neglected class of materials. The first screens with LC-based pixels appeared and the investigation of the LC physical and chemical properties was revived. In the next decade, a significant step occurred. Swiss watchmaker BWC (Buttes Watch Company) announced its clock based on LC technology in 1971, which was the first in history. This clock used the Dynamic Scattering principle to drive the display. That same year, $\mathrm{M}$. Schadt and W. Helfrich described a new electro-optic effect of nematic LC, known as a twist effect or TN (twisted nematic) mode [4]. By exploiting this effect, it was possible to fabricate a liquid crystal display (LCD), characterized by low consumption, low values of control voltage, high contrast and relatively fast response speeds [5]. Thanks to the absence of electrochemical degradation of the material, high lifetimes were achieved [6]. In the 1990s, engineers at Hitachi developed active control schemes (active-matrix addressing), thus taking a definitive step toward high-resolution displays [7].

Liquid crystal displays currently monopolize the market and are considered to be the most important LC-based application. Nevertheless, there are many more LC applications which are not related to displays. For example, LC can be used to dynamically tune the response of several components of optical communication networks, such as modulators [8], switches [9], multiplexers [10], filters [11], phase shifters [12], or fiber polarization controllers [13,14]. LC-tunable devices for the 
aerospace industry [15] or astronomy, performing, for instance, beam steering [16,17] or aberration control [18], have also been developed. The use of LC to control or modify signals at millimeter and sub-millimeter wave frequencies is another research field [19], in which several devices have been proposed, including, among others, tunable antennas [20], phase shifters [21], and filters [22].

Another application sector is the study of the interaction of metamaterials [23,24], nanoparticles [25-27], and carbon nanotubes with LC [28-31]. In particular, the interaction of light with metallic nanoparticles (e.g., gold or silver) presents an interesting phenomenon, known as Localized Surface Plasmon Resonances (LSPR). The LSPR properties can be modified by the presence of an analyte, as in the case of plasmon-based biosensors [32], or by an active medium, such as LCs [33]. When instead of isolated metallic nanoparticles a continuous metal film interacts with light, propagating waves can emerge, known as Surface Plasmon Polaritons (SPP), which provide deep subwavelength confinement. By tuning the SPP properties with an LC material, plasmonic modulators can be designed [34-36]. The LC molecular orientation is very sensitive to changes at the interface between the LC and the surrounding materials. By adding an analyte that allows some kind of binding with the LC or the alignment surface, the LC orientation can be strongly affected by the presence of microparticles such as bacteria, introducing disorder into the area around the binding zone. Hence, LC can make unique optical probes for imaging the molecular ordering and chemical patterns of organic surfaces and sensing the chemical reactions such as enzymatic reactions, DNA hybridization, ligand-receptor bindings, and peptide-lipid interactions at the LC/aqueous interface [37,38]. The same concept is also exploited in other fields, such as security, using LC devices based on different alignments that boost them with particular characteristics of visualization [39].

Furthermore, the dependence of the LC properties on various physical parameters such as deformation, electrical and magnetic fields, pressure and temperature, in addition to the easy integration of LCs in fiber-optics, makes them ideal candidates for the development of distributed sensors [40,41]. For instance, LC are employed in temperature sensing, owing to their high thermo-optic coefficient [42], for instance, in Fabry-Perot systems [43], photonic crystal fibers [44] and chiral nematic polymer networks [45], micrometric structures [46,47], mixtures of LC and metallic nanoparticles in Fabry-Perot [48] or fiber-optic cavities [49].

Finally, LC-tunable optical phase modulation is another application, which has attracted significant attention recently [50], where a large number of techniques and processes have been proposed. Nowadays, it remains a hot research topic, e.g., in ophthalmological applications [51], tunable zooming [52], beam steering [53], correction of aberrations [54], astronomy [55], 3D vision applications [56-59], novel aberration correctors for rectangular apertures [60], micro-axicon arrays [61], multi-optical elements [62], multi-focal [63], high fill-factor [64] and frequency-controlled [65] microlenses, optical vortices [66-69], lensacons, and logarithmic axicons [70]. Among all such applications, adaptive-focus lenses have been the most intensively researched topic during the last 40 years.

The next section describes briefly the state-of-the-art LC-based adaptive lenses. Over the years, numerous concise reviews on the topic of LC lenses have been published. For this reason, this work is focused on recent advances in LC lenses with a diameter larger than $1 \mathrm{~mm}$. As this field is very active, in recent years, several new structures and materials have been proposed, which are reviewed in Section 3. In addition, novel applications have emerged in which LC lenses play a major role. In the last section, we discuss the advantages and disadvantages of the reported technologies and highlight the future prospects and challenges in the technology of adaptive-focus LC lenses.

\section{Adaptive-Focus Liquid Crystal Lenses}

An adaptive-focus lens is a device capable of tuning its focal length by means of the application of an external stimulus. Conventional lenses rely on two physical parameters in order to modify the impinging wavefront: (a) the difference between the refractive index of the lens material and the surrounding environment and (b) the curvature of their interfaces. For this reason, adaptive-focus 
lenses are based on devices that change either the refractive index of the lens material or the curvature of its interface. Several techniques for the development of adaptive-focus lenses have been proposed [71]. They can be categorized into three major groups: (a) sliding variable-power rigid lenses, (b) shape-changing fluidic lenses and (c) refractive-index-controlled LC lenses.

In the first group, the optical power is tuned by displacing complementary pieces of identic cubic surface profiles. This technique was independently proposed in the late 1960s by Luis Alvarez [72,73] and Adolph Lohmann [74], and today such lenses are known as Alvarez lenses. Whereas Alvarez' objective was a varifocal ophthalmic lens for presbyopia correction [73], Lohmann searched for a zooming lens system based on lateral rather than longitudinal shifts of lenses [74]. However, refractive Alvarez lenses are very difficult to fabricate due to their cubic surfaces. It was not until 30 years later when a practical device was fabricated by using diffractive plates [75], see Figure 1b. Recently, this technique has been proposed for miniature adaptive lenses [76], and high-speed focusing [77], as shown in Figure 1a. Some advantages are a broad optical power range and the possibility of fast switching.

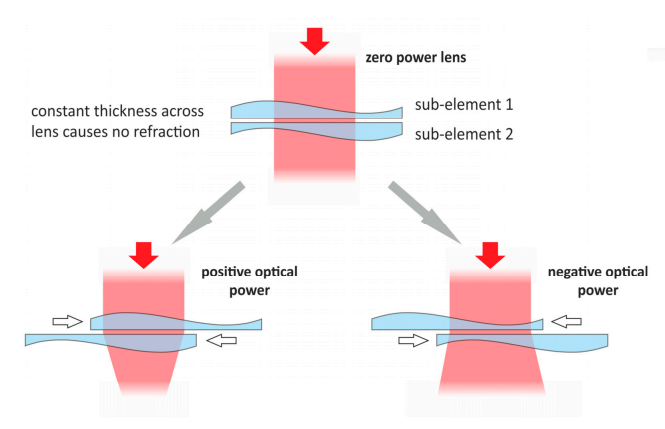

(a)

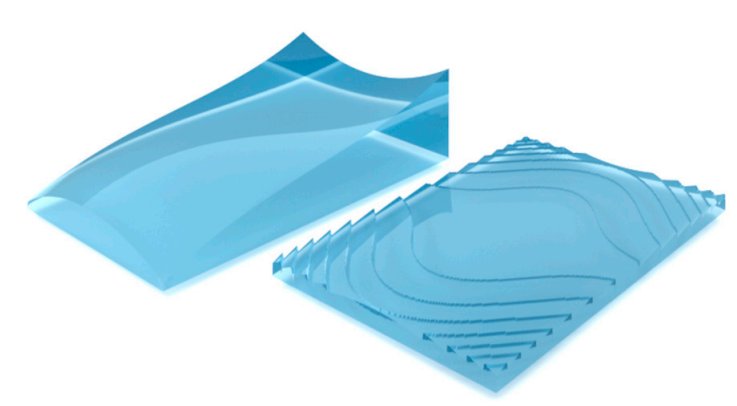

(b)

Figure 1. Working principle of the Alvarez lens: (a) a modulation of the optical power is obtained when conjugate phase plates are shifted with respect to each other in the direction where their phase profile is anti-symmetric. Depending on the displacement of the sub-elements from their zero position, a lens with positive or negative optical power is generated. (b) A refractive Alvarez sub-element with a profile function proportional to $x^{3} / 3+x^{2}$ and the corresponding diffractive Alvarez sub-lens, the phase pattern of which is generated by taking the refractive phase structure modulo $2 \pi$, are shown. Reprinted with permission from [77]. Copyright 2017 Optical Society of America.

In the case of shape-changing techniques, these can be categorized in the use of elastic membranes, ferrofluidics, soft electroactive actuators, and the electrowetting and dielectrophoretic effect. Depending on the technique, different characteristics can be obtained. For instance, in elastic membrane lenses, a liquid is sandwiched between two substrates of which one is made of an elastic membrane. The lens formation is based on fluidic pressure, by pumping liquid in or out of the lens cavity, which causes changes in the membrane profile accordingly. In order to pump the liquid, a piezoelectric actuator [78] or other mechanical methods [79-82] can be used. For example, in Figure 2a,b the arm of a servomotor deforms the rubber membrane, thus squeezing the liquid contained in the reservoir into the lens chamber. The cavity volume determines the optical power of this kind of lens. The material used to make the membrane is usually polydimethylsiloxane (PDMS). Some current challenges include shape distortion (deflection of the membrane is non-linear), gravitational effect (considerable as the membrane deformation increases), and mechanical actuation. Some improvement can be obtained with piston actuators [83]. Another piston actuator technique is based on ferrofluids [84-86], where the piston is tuned by magnetic fields. Advantages of this approach are large dynamic range and high optical performance. The main problem lies in the precise control of the focal length. One possible solution has been found in the use of soft electroactive actuators [87]. These actuators can be made of different materials, for example, photo-polymer [88-90], hydrogel gel [91,92], conducting polymer artificial muscle [93], ionic polymer-metal composite artificial muscle [94], carbon nanotube artificial 
muscle [95], dielectric elastomer actuator (DEA) artificial muscle $[96,97]$, and plasticized polyvinyl chloride (PVC) gel $[98,99]$. The main advantages are the size and easy control $(\mathrm{pH}$, temperature, light, magnetic field, or electric field).

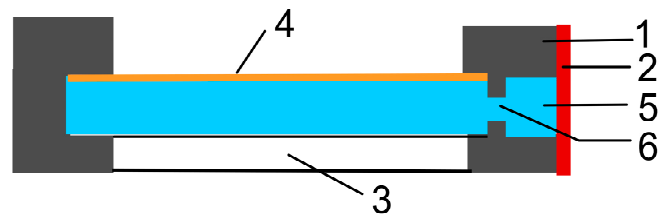

(a)

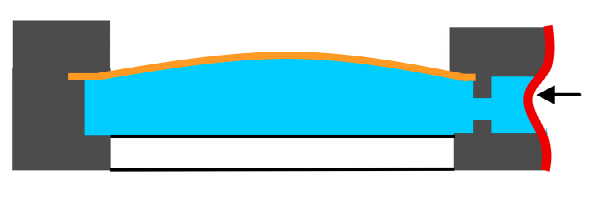

(b)

Figure 2. Side view of the liquid lens cell: (a) without and (b) with a convex lens profile. 1-annular sealing ring, 2-rubber membrane, 3-glass plate, 4-elastic membrane, 5-liquid, and 6-a hole. Reprinted with permission from [80]. Copyright 2006 Optical Society of America.

Other important techniques are electrowetting and dielectric lenses, which are based on liquid-liquid systems. In the latter case, a liquid forms a droplet, which is surrounded by a second liquid of a different type. In electrowetting-based lenses, an electrically conducting liquid drop (usually salt water) is placed in a dielectric-conducting surface, and the macroscopic contact angle can be tuned by changing the charges at the surface. When a control voltage is applied, the droplet tends to spread over a wider area in order to minimize the energy, as schematically shown in Figure 3a,b. Some advantages are the low gravitational effect, stability in case of shocks and vibrations, high optical power, and low response time. In the case of dielectric lenses, two non-conductive liquids with different dielectric constants are used $[100,101]$. The structure, control, and optical performance are very similar to electrowetting lenses. The main disadvantages of liquid-liquid systems are the operating voltage, the necessary thickness for large aperture lenses (in order to avoid the capillary effect), and possible reflection and scattering due to multiple interfaces.

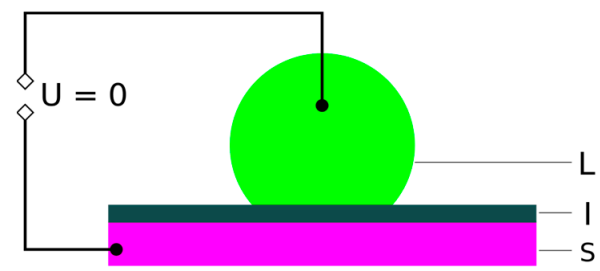

(a)

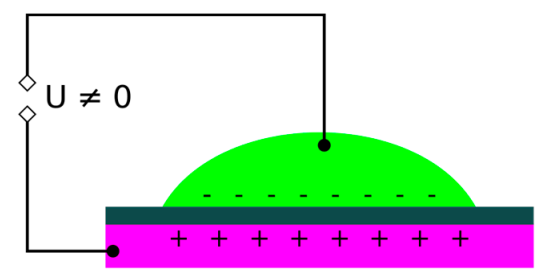

(b)

Figure 3. Basic diagram of the electrowetting principle: the change in the solid-electrolyte contact angle due to an applied potential difference between the solid and the electrolyte (a) without voltage; (b) with applied voltage. (L-Liquid, I-Isolator, S-Substrate, U-Potential). Under CC0 1.0 Universal, public domain dedication.

The last group of adaptive-focus lenses is based on the gradual variation of the refractive index, in principle, without the necessity of any curved interfaces. When light travels through a non-homogeneous medium, the speed of the wavefront decreases in the optically dense regions and accelerates in areas of lower density. Based on this mechanism, lenses without curvature are made by using a material with a spatial gradient of its refractive index; these devices are known as a GRIN (GRadex INdex) lens. In this respect, numerous approaches based on LC-lenses with an electrically controllable focal length have been successfully demonstrated. Many of the topologies proposed for LC lenses are based on generating a gradual voltage across the lens capable of reproducing a parabolic refractive index gradient in the LC layer, thus mimicking the optical behavior of a conventional lens. LC-lenses can substitute their conventional counterparts while being more compact and lightweight. Their true potential, though, lies in applications where a variable focal length is needed, which LC-lenses achieve with low driving voltages and low power consumption. 
Among the different LC-based applications, adaptive lenses have been at the forefront for more than 40 years. In the late 1970s, some pioneering research was carried out, giving rise to the first proposals of adaptive lenses, such as the works of Berreman et al. (with patent application in 1977 [102]) and Sato et al. in 1979 [103] (Figure 4a,b). The first adaptive lens was simply based on a curved cavity that was filled with LC. Some problems were the low response time, due to the increased LC layer thickness, and the molecular orientation homogeneity in the employed thick and curved layers. For these reasons, this particular technique was not further developed.

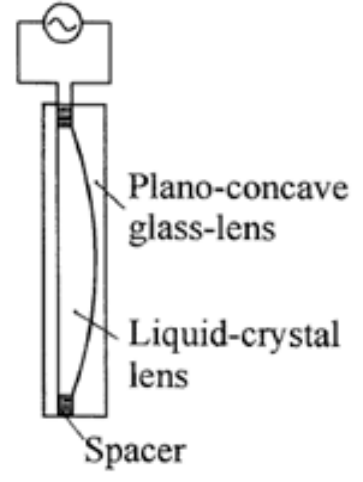

(a)

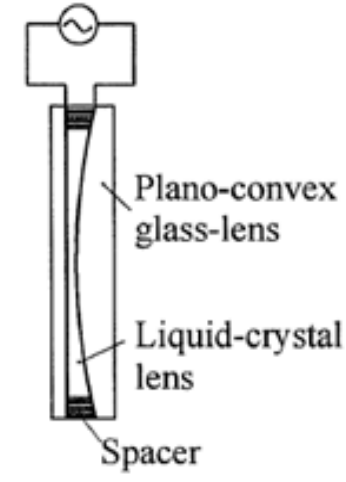

(b)

Figure 4. First proposals of liquid crystal (LC) lenses. (a) Plano-concave lens (b) Plano-convex lens. Reprinted with permission from [103]. Copyright 1979 IOP Science.

Some years later, in 1981 [104], the first cylindrical LC lens that was tunable by voltage was demonstrated by a group at Syracuse University, operating as an adaptive optical element. The structure was based on several electrodes that produced the desired voltage gradient. This new concept of lens stimulated other research works [105] and subsequently, spherical lenses [106]. In the late 1980s, new research works demonstrated LC lenses at the micrometric scale $[107,108]$. Around that time, the first Fresnel lenses were also reported [109]. This configuration reduced the necessary thickness and increased the diameters of the lenses. In the beginning, refractive Fresnel lenses based on surface relief profiles were proposed. Following that, diffractive Fresnel lenses and a mixed version (kinoform lens) were introduced. Also in the 1980s, A.F. Naumov et al. [110] proposed an improved patterned electrode lens to work with large apertures. By using a high-resistivity layer, voltage drop at the edges was avoided [111]. The sheet resistance of the control electrode is a key design parameter. Its value must be in the range between $100 \mathrm{k} \Omega / \mathrm{sq}$ and a few $\mathrm{M} \Omega / \mathrm{sq}$ for lens diameters in the order of millimeters [112]. This technique has also been proposed for wavefront correctors [54,113], multi-optical devices [114,115] or optical tweezers [116,117]. Intense research on this technique resulted in a commercial device by Flexible Optical B.V. (OKO Tech) [118] (Figure 5).

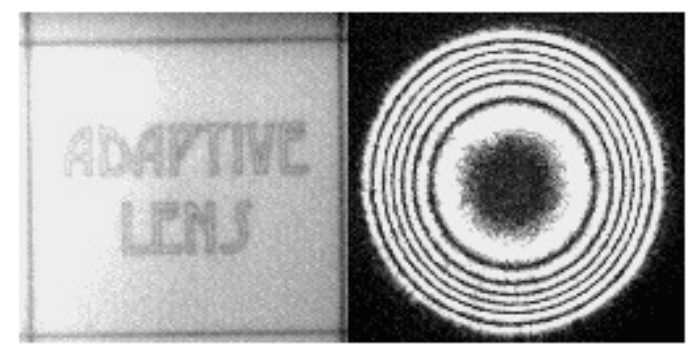

Figure 5. Commercial modal LC lens by Flexible Optical B.V. Reprinted with permission from [118].

In the following years, an exponential increase in research on LC lenses was experienced, which continues to this day, making adaptive-focus lenses one of the most important and researched topics 
in the field of LCs during the last 40 years. Over these years, several reviews have been published. Some recent reviews are focused on specific topics, such as fast response time LC microlenses [119], LC microlenses for autostereoscopic displays [120], design and fabrication [121] or LC contact lenses for the correction of presbyopia [122]. As a general approach, the review on LC lenses by Lin et al. is by far the most complete and detailed [123]. For this reason, the next section is only focused on recent developments in LC lenses with a diameter larger than $1 \mathrm{~mm}$. Despite the fact that the main structures were established several years ago, there is still room for new proposals.

\section{Recent Developments in Liquid Crystal Lenses}

Despite the fact that LC lenses were first reported 40 years ago, they still remain an active field of research. In general, the applications of LC lenses are as numerous as those of fixed lenses or GRIN lenses, with the great advantages of volume and weight reduction and tunable focal distance by voltage. For example, LC lenses can help realize auto-focusing and optical zoom systems [124]. They have also been proposed for pico-projection systems, helping to electrically adjust the focusing properties of the projected image without mechanically adjusting the position of a projection lens [125]. In the case of holographic projection systems, LC lenses can help to correct the mismatch of chromatic image size, which is important for full-color holographic projection systems [126]. LC lenses can also be used as a concentrator and a sun tracker in a concentrating photovoltaic (CPV) systems [127] or couplers for fiber optics [128].

Furthermore, it is worth mentioning the use of LC lenses in the field of bio-optics, e.g., as optical tweezers [116,129], or in medical instrumentation in applications such as endoscopy, where LC lenses can be adopted to electrically enlarge the depth-of-field of an endoscopic system [130]. In addition, when it comes to ophthalmic lenses, the lens power of LC lenses is not only electrically tunable but it can also be positive or negative. LC lenses can correct myopia, hyperopia, and presbyopia. In the case of novel augmented reality displays, it can alleviate problems for people with disabilities and resolve the issue of accommodation-convergence [131]. In this regard, contact lenses made from LCs have been proposed [132-135], as well as LC-based commercial glasses, which were developed in 2011 [136] (Figure 6). Although such glasses tackle the problem of patients who require different types of glasses for different activities, the company went bankrupt due to a high rate of return (battery issues and some defective devices). LC lenses can also be considered as a kind of "extra-artificial crystalline lens" to compensate for the degradation of the crystalline lens of aging eyes or eye accommodation [137].

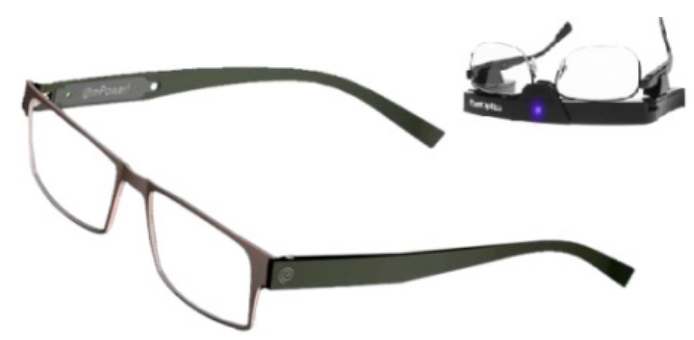

Figure 6. Commercial LC glasses with tunable focus (PixelOptics) [136].

In short, in recent years there have been lots of developments tailored to the needs of different applications. These works can be grouped as a function of the employed technique. In this review, they are divided into the following categories: curved lenses, patterned electrodes, modal control, alignment layer, Fresnel, and polarization-independent lenses.

\subsection{Curved Lenses}

As previously mentioned, this technique was the first proposal for an LC lens due to the similarity to classic lenses. Despite this, in recent years intense research on applying this concept to contact lenses has been produced. For example, a switchable polymethyl methacrylate (PMMA) LC lens to function 
as a contact lens was proposed, as shown in Figure 7a,b [134]. The device has an active optical zone of $4 \mathrm{~mm}$ and it produces a variable focal power of up to +2.00 diopters, perfect for presbyopia correction. The same group has demonstrated that the use of negative LC and vertical alignment in the same structure provides a continuous change in focal power up to -2.00 [138]. The design considerations for this type of lens are reported in [139]. Other proposals that rely on the use of flexible substrates can be found in [140], using polyethylene terephthalate (PET) as a substrate. Two display substrates with different surface areas are used, allowing for the integration of powering and driving electronics (the purpose is also to work as a contact lens). The authors claim that ring-shaped concentric pixels, which are able to switch from a transparent to an opaque state, can be used to mimic an ocular iris and that it could be used by people suffering from iris deficiencies that involve hypersensitivity to light, such as aniridia, coloboma, or ocular albinism [140].

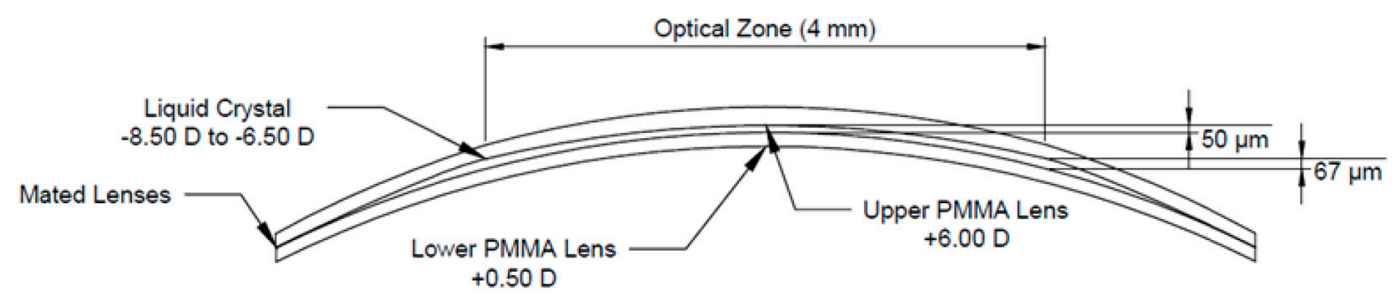

(a)

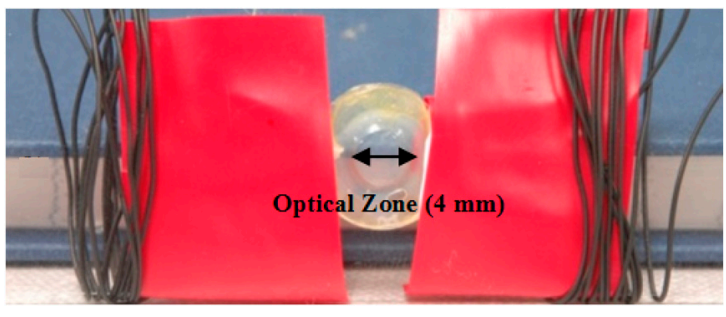

(b)

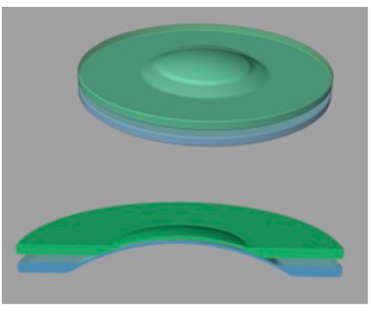

(c)

Figure 7. (a) Shows a diagram of the design used for the switchable LC lens. The base curve of the lens is designed to fit onto the eye, with a radius of curvature of $7.8 \mathrm{~mm}$, and therefore, appropriate for the average human cornea. The optical power of the lower substrate is $+0.50 \mathrm{D}$, the optical power of the upper substrate is $+6.00 \mathrm{D}$, with the optical power of the LC layer varying between $-8.50 \mathrm{D}$ and $-6.50 \mathrm{D}$, depending on the polarization direction of light and the orientation of LC molecules. (b) A photograph of the device. (c) CAD rendered images of the lens. Reprinted with permission from [134]. Copyright 2014 Optical Society of America.

Another option is to embed dielectric curved elements inside the cell. This technique has been used extensively to produce LC microlenses; however, the main challenge is the necessary thickness of these elements. An array of LC lenses with diameters of $1.2 \mathrm{~mm}$ is demonstrated in [141]. The optical power can be switched from +100 to +50 diopters for voltages ranging from 11 to $14 V_{R M S}$, respectively.

\subsection{Patterned Electrode}

This category comprises designs that have patterned Indium tin oxide (ITO) in the structure. This was the first technique proposed to design LC microlenses, and involved exploiting a basic mechanism. A hole in the ITO layer produces a voltage decrease toward the lens center that has a quasi-parabolic profile. The main problem is that for diameters larger than the thickness of the sample, the voltage drops at the edges. Several structures have been recently proposed to counter this problem. In [142,143], a floating ring electrode is embedded in the interface between the dielectric layer and the LC layer. A diameter of $6 \mathrm{~mm}$ was reported and the operating voltage range was from 0 to $40 \mathrm{~V}_{\mathrm{RMS}}$. For the 
maximum voltage, an optical power of +8.33 diopters was achieved. A different approach has been proposed in [144], by using internal resistances between electrodes to conduct the voltage towards the center. In [145], a multielectrode configuration is proposed, which is different from previous designs in that only one lithographic step is necessary (Figure 8a-d). All the electrodes are located on the same layer. Although it is a microlens, it is included because the diameter can easily be scaled to larger values. The main problem is that the higher the number of control voltages, the larger the defect area (see Figure $8 b$ ) in the active region in the lens area, thus limiting the maximum diameter.

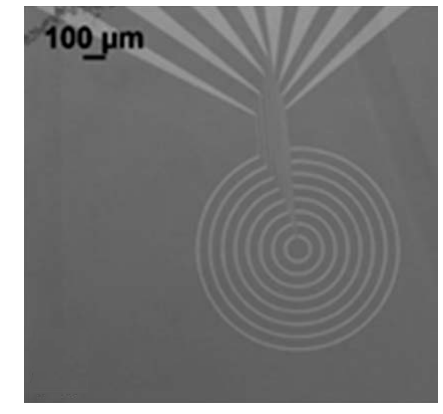

(a)

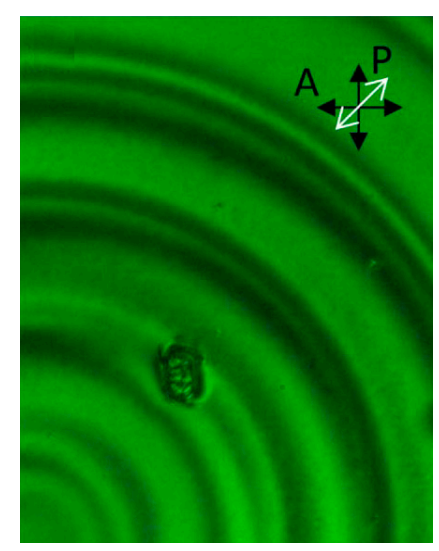

(c)

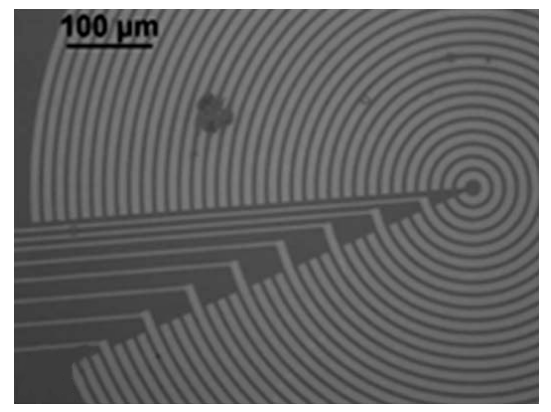

(b)

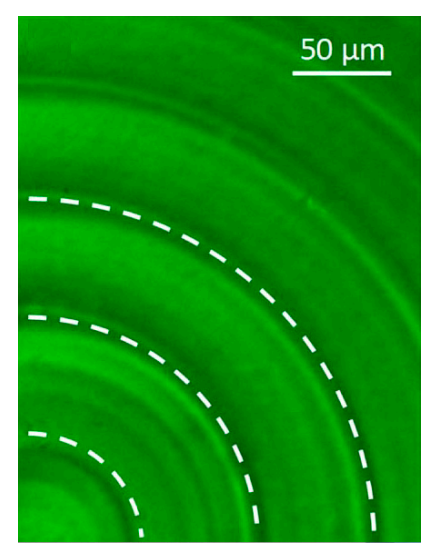

(d)

Figure 8. Reflection microscope image of the ITO electrode pattern for a lens (a) without floating electrodes and (b) with floating electrodes. Polarization microscope image of the LC devices with PZT (c) without floating electrodes and (d) with floating electrodes when $5 \mathrm{~V}$ is applied to all the electrodes. The rubbing direction is denoted with a white arrow. The position of the contacted electrodes is indicated with a white dashed line. Reprinted with permission from [145]. Copyright 2018 Optical Society of America.

\subsection{Modal Control}

This technique was also among one of the first ones to be proposed, and the advances during the last 40 years are related to the use of different materials for the high-resistivity layer, among which titanium oxide films [146], thin ITO layers [147] (max. $10 \mathrm{M} \Omega / \mathrm{sq}$ [148]) or PEDOT [149].

In recent years, novel materials have been proposed, such as those used in [150], where a multi-functional liquid-crystal lens based on a dual-layer electrode design have been demonstrated. The diameter was $1.42 \mathrm{~mm}$ and the material for the high-resistivity layer was niobium pentoxide $\left(\mathrm{Nb}_{2} \mathrm{O}_{5}\right)$. As with other materials, the optimization of the fabrication process is key in order to obtain stable parameters. Depending on the conditions, a broad range of sheet resistance values are obtained. One of the main problems of modal control, despite being the best technique in terms of simplicity and 
power consumption, is that the manufacturing of homogenous high-resistivity layers is not trivial to obtain. A high-resistivity layer of $\mathrm{ZnO}(100 \mathrm{M} \Omega / \mathrm{sq})$ is employed in [151], where the thickness of the LC layer is $30 \mu \mathrm{m}$, the diameter $2 \mathrm{~mm}$, and the optical power can be tuned from -3.9 to +4.4 diopters by using two different voltages. In [152], a PEDOT layer is used, but the electro-optical features of the LC lens are improved by doping the LC with multi-walled carbon nanotubes. The thickness of the LC layer is $100 \mu \mathrm{m}$ and the diameter is $2.3 \mathrm{~mm}$. When the external applied voltage is adjusted from 0 to $5 \mathrm{~V}_{\mathrm{RMS}}$, the lens power switches from +1.92 to +83.33 diopters. Additionally, the response time is reduced to $0.1 \mathrm{~s}$ in comparison with $2.6 \mathrm{~s}$ for non-doped cells. Another material recently proposed is an oxide Ag alloy [153]. Moreover, as claimed by the authors, the addition of a floating electrode allows significant optimization of the spatial distribution of the electrical potential (Figure $9 a, b)$. The spherical aberration is reduced considerably, thus obtaining a high-quality lens. The lens has been tested in an 8-megapixel miniature camera of a cell phone [154]. Finally, different modifications for the modal control technique (based on inner and floating electrodes) are analyzed in [155]. It is claimed that it is possible to obtain a parabolic wavefront across the entire clear aperture of the lens. The proposed design has a $4 \mathrm{~mm}$ clear aperture, very low RMS spherical aberrations, and a dynamic range of +3.5 diopters.

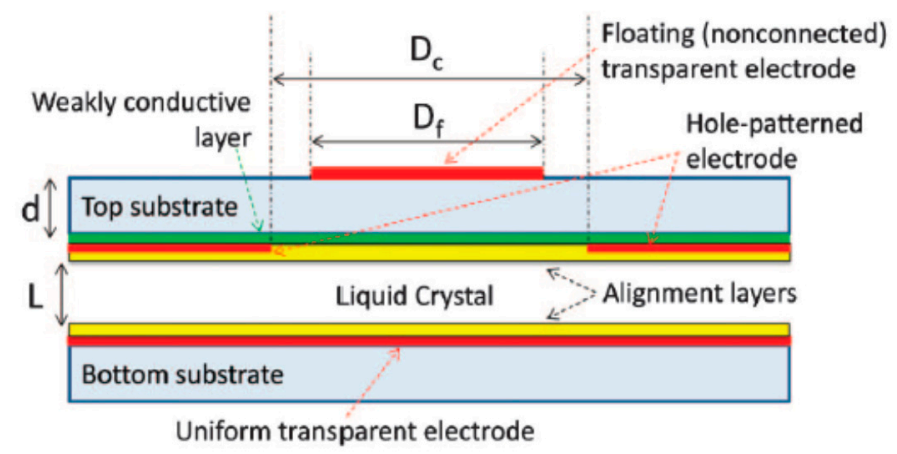

(a)

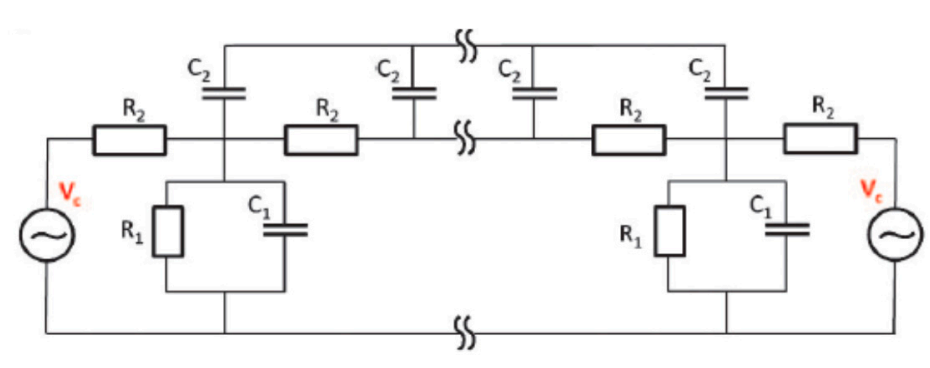

(b)

Figure 9. (a) Schematic presentation of the structure of the proposed modal LC lens, and (b) its approximate equivalent electrical circuit. $\mathrm{V}_{\mathrm{c}}$ is the control voltage (applied on the hole patterned electrode); $R_{1}$ and $C_{1}$, are the equivalent electric resistance and capacitance of the LC cell, respectively; $R_{2}$, is the equivalent resistance of the high-resistivity layer; $C_{2}$, the equivalent capacitance due to the floating electrode. Reprinted with permission from [153]. Copyright 2016 Optical Society of America.

\subsection{Aligment Layer}

This technique is usually based on the use of polymers which are sensitive to UV radiation as alignment layers [156]. Varying the UV dosage controls the pretilt angle. In recent years, new materials have been investigated, typically, these have been photosensitive polymers with benzaldehyde side groups. In references $[157,158]$, a variable pretilt in the range from $0^{\circ}$ to $90^{\circ}$ is achieved via the formation of a localized polymer network. Other examples have used a new polymer characterized 
by the percentage of the three components and its macromolecules, comprising of photosensitive benzaldehyde-containing fragments (B), methacrylate fragments, causing vertical LC alignment (VA), and methacrylate fragments, producing planar LC alignment under photocrosslinking of the material, as investigated in [159]. The main difference with other materials is the two-step treatment: uniform rubbing (defines the azimuthal angle) and gradient nonpolarized UV exposure (to define the pretilt angle). Photocrosslinkable benzaldehyde polymers with fragments including long hydrocarbon substituents in a side chain are used in [160].

A different approach is the use of photoalignment to create Pancharatnam-Berry lenses. In [161], an LC lens with a diameter of $16 \mathrm{~mm}$ and an optical power of +27.7 diopters ( $99 \%$ diffraction efficiency) is reported. The thickness of the LC layer is only a few $\mu \mathrm{m}$ so the response time is reduced. As reported in [162], this kind of lens exhibits a fast switching time between two or more focal lengths with a large diopter change and aperture size (Figure 10a-d). In order to fabricate such a lens, a photo-alignment material is coated onto the substrate. The cell is mounted and subject to interference exposure. Another method to produce Pancharatnam-Berry lenses is proposed in [163]. In this case, a ferroelectric liquid crystal (FLC) cell with a continuous alignment structure is realized by a polarization holographic method. Authors report a diffraction efficiency of up to $87 \%$ and a response time of $300 \mu$ s with a low electric voltage $(4 \mathrm{~V} / \mu \mathrm{m})$. The optical power can reach +2.4 diopters for a $13 \mathrm{~mm}$ aperture. This type of lens has been proposed to solve the problem of accommodation-convergence in head-mounted display devices $[164,165]$ and to generate spatially separated focuses [166].

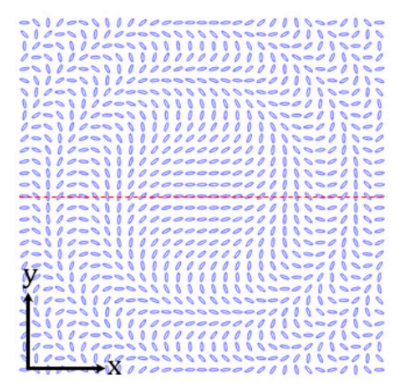

(a)

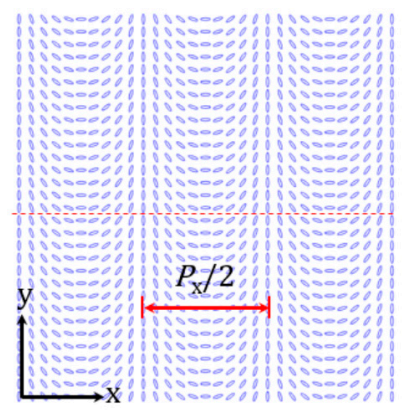

(c)

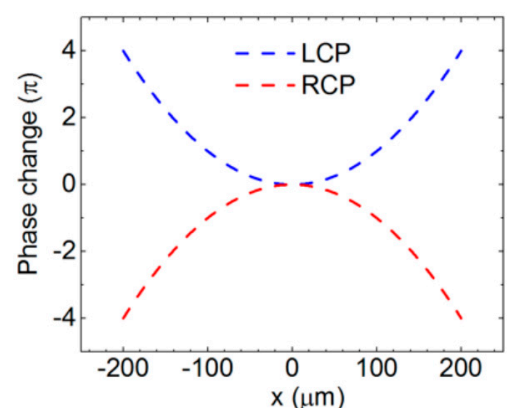

(b)

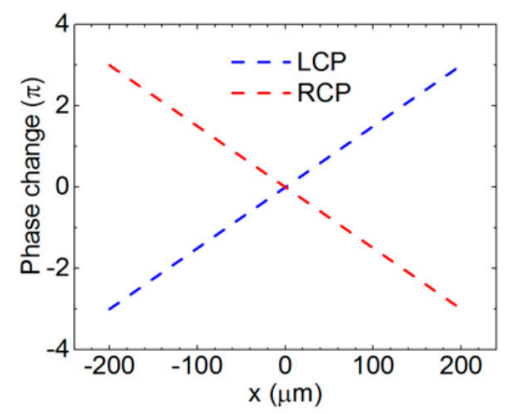

(d)

Figure 10. (a) Top view of a Pancharatnam-Berry lens: the direction of the LC optical axis changes radially. (b) The corresponding phase change along the dashed lines in (a). (c) Top view of a Pancharatnam-Berry deflector: the direction of the LC optical axis changes longitudinally. (d) The corresponding phase change along the dashed lines in (c). Reprinted with permission from [162]. Copyright 2017 Optical Society of America. 


\subsection{Fresnel}

Fresnel lenses have been investigated since the beginning of research on LC lenses. It is the most viable option to obtain high optical powers with large aperture diameters. At the beginning, refractive Fresnel lenses based on surface relief profiles were proposed. After that, diffractive Fresnel lenses and a mixed version (kinoform lens) were introduced. In these 40 years, there have been several proposals to obtain this type of structure.

In recent years, some cases include refractive Fresnel lenses [167] and diffractive Fresnel lenses, in which the zones are made by confining ferroelectric liquid crystals (FLCs) in multiple microscopically defined photo-aligned alignment domains [168] (Figure 11a,b); by multi-electrodes [169]; polymer-dispersed liquid crystal [170]; by a $90^{\circ}$ twisted-nematic liquid crystal (LC) cell with a photoconductive polymer layer [171]; by using a photoconductive polymer layer and a Sagnac interferometer [172]; by a P6CB alignment layer (orientation direction also controlled along the polarization direction of UV light) and an interferometric setup [173]; by a patterned hybrid photo-aligned nematic dual frequency LC [174]; by Polymer-Stabilized Blue Phase (PSBP) LC zones [175-177] (the lenses being also polarization-independent). In these cases, the thickness is considerably reduced (between $1.5 \mathrm{um}$ to $12 \mathrm{um}$ ), and therefore, the switching is fast. The optical power can be very high ranging from +1.5 to +23 diopters. The main disadvantage of these designs is the low diffraction efficiency obtained (around $30-40 \%$ for a binary phase lens).

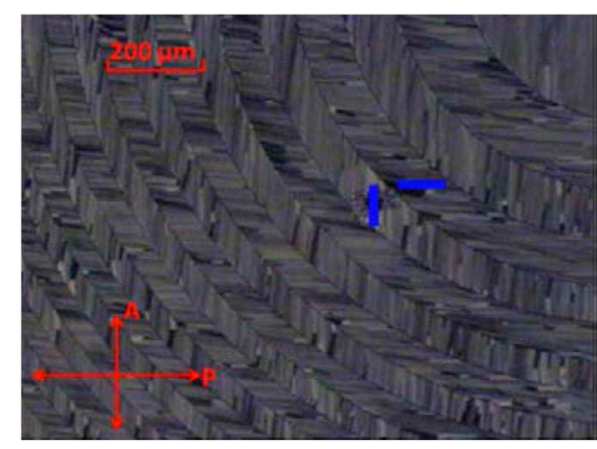

(a)

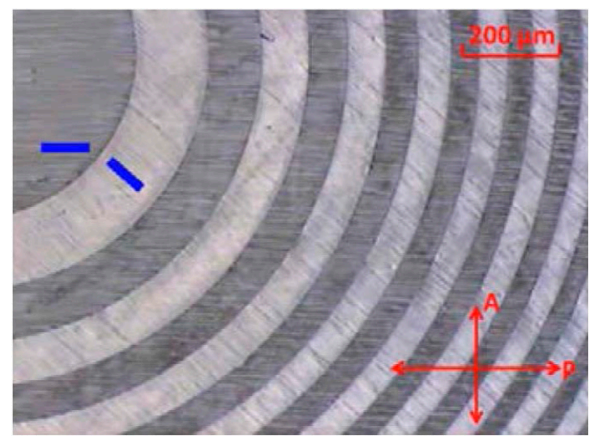

(b)

Figure 11. Microphotographs of two designed ferroelectric liquid crystal Fresnel zone lens under crossed polarizers. The blue lines indicate the alignment directions. (a) ferroelectric liquid crystal Fresnel zone lens (Rin $360 \mu \mathrm{m}$ ) with $\beta 90^{\circ}$. (b) ferroelectric liquid crystal Fresnel zone lens (Rin $255 \mu \mathrm{m}$ ) with $\beta 45^{\circ}$. Reprinted with permission from [168]. Copyright 2015 Optical Society of America.

\subsection{Polarization-Independent Lenses}

Polarization-independent lenses are very interesting from a practical point of view. They do not require external polarizers and usually provide high optical power. As commented in the previous section, PSBP-LC Fresnel lenses are one example of polarization-independent lenses, yet other approaches based on this material can be found in [178], where a matched conventional glass lens is introduced in a Blue Phase Liquid Crystal (BPLC) lens to increase the range of the tunable focal length. The main problem associated with this material is the high voltage required to change the refractive index. In addition to PSBP LC, this effect can be achieved by stacking two LC lenses orthogonally. In recent years, some advanced structures have been proposed. For example, by stacking a number of LC layers, the aperture size of the LC lens can be enlarged without lowering the tunable lens power [179] (Figure 12a-c). 


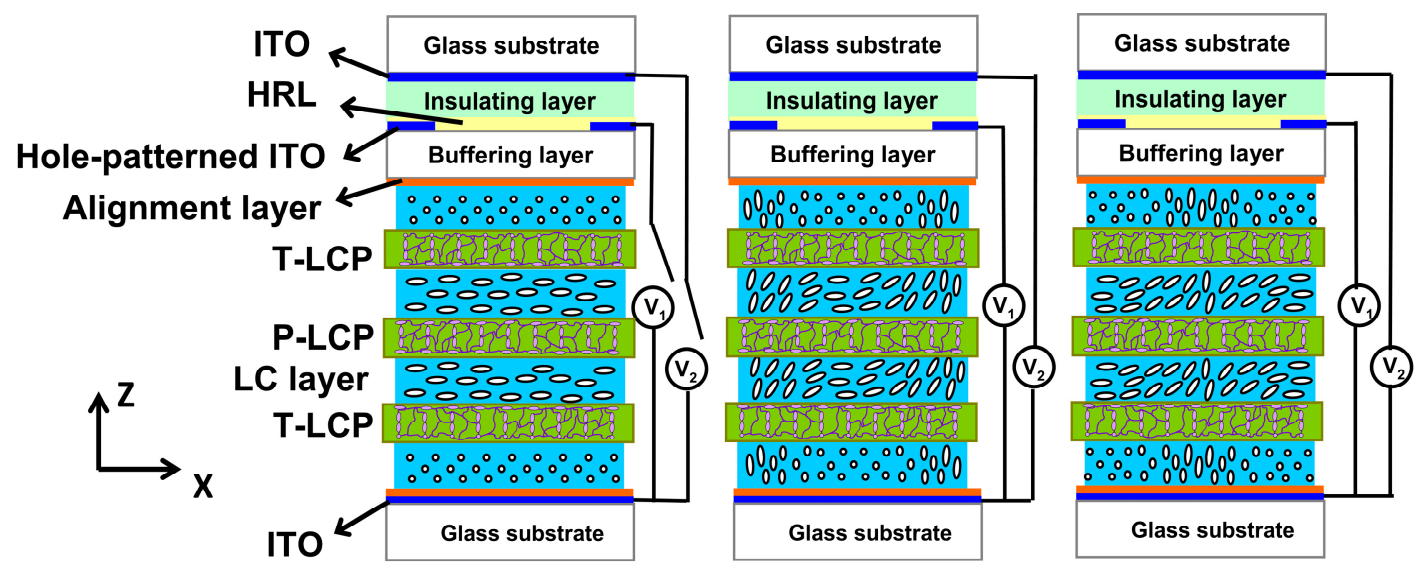

(a)

(b)

(c)

Figure 12. Schematic diagrams of the operation of the multilayered LC lens at (a) voltage-off state, (b) $V_{1}>V_{2}$ and (c) $V_{2}>V_{1}$. (C) 2015 IEEE. Reprinted, with permission, from [179].

For a large aperture of $10 \mathrm{~mm}$, the reported switching time is $\sim 3 \mathrm{~s}$ for imaging objects from $360 \mathrm{~cm}$ to $26 \mathrm{~cm}$. The lens power is +3.93 diopters for a driving voltage of $80 \mathrm{~V}_{\mathrm{RMS}}$. These are promising values for an LC lens with such a diameter. This design can solve several classic problems of LC lenses, such as the necessity of thick devices for high optical power, the derived response time of thick devices, and the polarization dependency of LC lenses. Another recently demonstrated approach is by using Pancharatnam-Berry lenses with a specific configuration [180]. The structure consists of at least four Pancharatnam-Berry lenses, with specific distances between them. As the authors claim, by compensating the polarization dependency of each Pancharatnam-Berry lens, single-depth high-resolution images can be obtained without preprocessing the incident polarization state.

\section{Discussion}

Adaptive-focus lenses have attracted a great amount of scientific and technological interest in recent years. Each technique discussed in this short review has its own strengths and weaknesses. For small apertures (less than $5 \mathrm{~mm}$ ), LC lenses have been demonstrated to be the most suitable option. Some techniques are very easy to fabricate, the operating voltages and power consumption are very low and the long-term stability is very high owing to the lack of mechanically moving parts. The main problem of larger apertures is that, for the same gradient of the refractive index, the higher the aperture the lower the optical power. Another problem is the thickness, which has to be large in order to obtain a large dynamic focus range, and thin to obtain a low response time, thus defining a trade-off in performance. For larger apertures, liquid lenses could be more appropriate, as the optical path length change is high due to the change in the shape of the material. Moreover, liquid lenses have lower response times and are polarization-independent. In this regard, some proposals for LC lenses as multilayer lenses have solved the problem of polarization dependency and switching time. For high optical powers, curved lenses appear to be a good option, as demonstrated by recent proposals that offer flexible solutions for contact lenses. Fresnel lenses can also produce high optical powers, but without the possibility of analog tunability. Many different materials have been proposed in recent years. When the optical power or response times are not the main requirement, modal lenses are a promising option since they feature lower power consumption, low voltage control, and simple fabrication. Some new materials for high-resistivity layers and minor modifications to the structure have demonstrated high-quality lensing and a dynamic focus range (from -3.9 to +4.4 diopters for an aperture of $2 \mathrm{~mm}$ ). Furthermore, other works have shown the potential of parabolic phase profiles for a $4 \mathrm{~mm}$ diameter with very low RMS spherical aberrations and a dynamic range of +3.5 diopters. 
Finally, new designs based on the smart control of alignment layers have appeared recently. The Pancharatnam-Berry lenses are worth mentioning as they exhibit a fast switching time between two or more focal lengths, high optical power for large apertures, and very thin layers, in the order of a few micrometers. These properties make them suitable for new applications, such as augmented reality devices.

In conclusion, LC lenses continue to attract the interest of researchers, mainly owing to the large number of applications in which they can be applied. Some new devices, such as head-mounted displays, mobile cameras, or contact lenses have demonstrated the need for novel adaptive lenses. One of the main challenges in the field of LC lenses is achieving the ability to increase the apertures to more than $10 \mathrm{~mm}$ while maintaining a high optical power (more than 3 diopters). Depending on the specific application, some parameters such as response time, dispersion, operation voltage, and phase profile must be taken into account. In the following years, novel materials and structures can potentially solve most of these problems, thus making LC lenses one of the most suitable platforms for the design of a novel class of adaptive-focus lenses for emerging applications.

Author Contributions: All authors contributed equally to the manuscript.

Funding: This work was supported by Comunidad de Madrid and FEDER Program under grant S2018/NMT-4326 and the Ministerio de Economía y Competitividad of Spain (TEC2013-47342-C2-2-R).

Conflicts of Interest: The authors declare no conflict of interest.

\section{References}

1. Lehmann, O. Über fliessende Krystalle (On flowing crystals). Z. Phys. Chem. 1889, 4, 462-472.

2. Friedel, M.G. The Mesomorphic states of matter. Ann. Phys. (Paris) 1922, 18, 162-174.

3. Heilmeier, G.H. Guest-host interactions in nematic liquid crystal. A new electro-optic effect. Appl. Phys. Lett. 1968, 13, 91. [CrossRef]

4. Schadt, M.; Helfrich, W. Voltage-dependent optical activity of a twisted nematic liquid crystal. Appl. Phys. Lett. 1971, 18, 127. [CrossRef]

5. Kawamoto, H. The history of liquid-crystal displays. Proc. IEEE 2002, 90, 460-500. [CrossRef]

6. Libsh, F.R.; Kanichi, J. TFT lifetime in LCD operation. In 1993 SID International Symposium: Digest of Technical Papers; Society for Information Display: Playa del Rey, CA, USA, 1993.

7. Lueder, E. Liquid Crystal Displays: Addressing Schemes and Electro-Optical Effects (Wiley Series in Display Technology); Wiley: Hoboken, NJ, USA, 2001; ISBN 0471490296.

8. Residori, S.; Bortolozzo, U.; Peigné, A.; Molin, S.; Nouchi, P.; Dolfi, D.; Huignard, J.P. Liquid crystals for optical modulation and sensing applications. In Proceedings of the SPIE 9940, Liquid Crystals XX, 99400N, San Diego, CA, USA, 22 November 2016.

9. Pinzón, P.J.; Pérez, I.; Vázquez, C.; Sánchez Pena, J.M. Reconfigurable $1 \times 2$ wavelength selective switch using high birefringence nematic liquid crystals. Appl. Opt. 2012, 51, 5960. [PubMed]

10. Lallana, P.C.; Vázquez, C.; Vinouze, B.; Heggarty, K.; Montero, D.S. Multiplexer and variable optical attenuator based on PDLC for polymer optical fiber Networks. Mol. Cryst. Liq. Cryst. 2009, 502, 130-142. [CrossRef]

11. Pinzon, P.J.; Vazquez, C.; Perez, I.; Sanchez Pena, J.M. Synthesis of Asymmetric Flat-Top Birefringent Interleaver Based on Digital Filter Design and Genetic Algorithm. IEEE Photonics J. 2013, 5, 7100113. [CrossRef]

12. Koeberle, M.; Hoefle, M.; Chen, M.; Penirschke, A.; Jakoby, R. Electrically tunable Liquid Crystal phase shifter in antipodal finline technology for reconfigurable W-Band Vivaldi antenna array concepts. Antennas Propag. 2011, 1536-1539.

13. Zografopoulos, D.C.; Kriezis, E.E. Tunable Polarization Properties of Hybrid-Guiding Liquid-Crystal Photonic Crystal Fibers. J. Light. Technol. 2009, 27, 773-779. [CrossRef]

14. Pitilakis, A.K.; Zografopoulos, D.C.; Kriezis, E.E. In-Line Polarization Controller Based on Liquid-Crystal Photonic Crystal Fibers. J. Light. Technol. 2011, 29, 2560-2569. [CrossRef] 
15. Geday, M.A.; Quintana, X.; Otón, E.; Cerrolaza, B.; Lopez, D.; de Quiro, F.G.; Manolis, I.G.; Short, A. Development of liquid crystal based adaptive optical elements for space applications. In Proceedings of the ICSO 2010 International Conference on Space Optics, Rhodes, Greece, 4-8 October 2010.

16. Oton, E.; Morawiak, P.; Mazur, R.; Quintana, X.; Geday, M.A.; Oton, J.M.; Piecek, W. Diffractive and refractive liquid crystal devices based on multilayer matrices. J. Light. Technol. 2019, 37, 2086-2093. [CrossRef]

17. Oton, E.; Perez-Fernandez, J.; Lopez-Molina, D.; Quintana, X.; Oton, J.M.; Geday, M.A. Reliability of liquid Crystals in Space Photonics. IEEE Photonics J. 2015, 7, 1-9. [CrossRef]

18. Hu, L.; Xuan, L.; Cao, Z.; Mu, Q.; Peng, Z.; Liu, Y.; Yao, L.; Yang, C.; Lu, X.; Xia, D.L.M. The state of the art for liquid crystal adaptive optics in astronomical applications. In Proceedings of the 2012 International Conference on Optoelectronics and Microelectronics, Changchun, China, 23-25 August 2012; pp. 428-430.

19. Zografopoulos, D.C.; Ferraro, A.; Beccherelli, R. Liquid-crystal high-frequency microwave technology: materials and characterization. Adv. Mater. Technol. 2018, 4, 1800447. [CrossRef]

20. Gaebler, A.; Moessinger, A.; Goelden, F.; Manabe, A.; Goebel, M.; Follmann, R.; Koether, D.; Modes, C.; Kipka, A.; Deckelmann, M.; et al. Liquid crystal-reconfigurable antenna concepts for space applications at microwave and millimeter waves. Int. J. Antennas Propag. 2009, 2009, 1-7. [CrossRef]

21. Muller, S.; Scheele, P.; Weil, C.; Wittek, M.; Hock, C.; Jakoby, R. Tunable passive phase shifter for microwave applications using highly anisotropic liquid crystals. In Proceedings of the IEEE MTT-S International Microwave Symposium Digest (IEEE Cat. No.04CH37535), Fort Worth, TX, USA, 6-11 June 2004.

22. Urruchi, V.; Marcos, C.; Torrecilla, J.; Sánchez-Pena, J.M.; Garbat, K. Note: Tunable notch filter based on liquid crystal technology for microwave applications. Rev. Sci. Instrum. 2013, 84, 026102. [CrossRef] [PubMed]

23. Zografopoulos, D.C.; Beccherelli, R. Tunable terahertz fishnet metamaterials based on thin nematic liquid crystal layers for fast switching. Sci. Rep. 2015, 5, 13137. [CrossRef] [PubMed]

24. Isić, G.; Vasić, B.; Zografopoulos, D.C.; Beccherelli, R.; Gajić, R. Electrically tunable critically coupled terahertz metamaterial absorber based on nematic liquid crystals. Phys. Rev. Appl. 2015, 3, 064007. [CrossRef]

25. Hegmann, T.; Qi, H.; Marx, V.M. Nanoparticles in liquid crystals: Synthesis, self-assembly, defect formation and potential applications. J. Inorg. Organomet. Polym. Mater. 2007, 17, 483-508. [CrossRef]

26. Pratibha, R.; Kumar, S.; Raina, K.K. Effect of dispersion of gold nanoparticles on the optical and electrical properties of discotic liquid crystal. Liq. Cryst. 2014, 41, 933-939.

27. García-Cámara, B.; Algorri, J.; Urruchi, V.; Sánchez-Pena, J. Directional scattering of semiconductor nanoparticles embedded in a liquid crystal. Materials 2014, 7, 2784-2794. [CrossRef] [PubMed]

28. Lee, G.S.; Lee, J.H.; Kim, J.C.; Yoon, T.-H.; Kim, J.-H.; Yu, J.-H.; Choi, H.-Y. Nanoparticle doped in-cell retarder for low operating voltage in transflective liquid crystal displays. Jpn. J. Appl. Phys. 2009, 48, 042405. [CrossRef]

29. García-García, A.; Vergaz, R.; Algorri, J.F.; Quintana, X.; Otón, J.M. Electrical response of liquid crystal cells doped with multi-walled carbon nanotubes. Beilstein J. Nanotechnol. 2015, 6, 396-403. [CrossRef] [PubMed]

30. García-García, A.; Vergaz, R.; Algorri, J.F.; Zito, G.; Cacace, T.; Marino, A.; Otón, J.M.; Geday, M.A. Reorientation of single-wall carbon nanotubes in negative anisotropy liquid crystals by an electric field. Beilstein J. Nanotechnol. 2016, 7, 825-833. [CrossRef] [PubMed]

31. García-García, A.; Vergaz, R.; Algorri, J.F.; Geday, M.A.; Otón, J.M. The peculiar electrical response of liquid crystal-carbon nanotube systems as seen by impedance spectroscopy. J. Phys. D Appl. Phys. 2015, 48, 375302. [CrossRef]

32. García-Cámara, B.; Gómez-Medina, R.; Sáenz, J.J.; Sepúlveda, B. Sensing with magnetic dipolar resonances in semiconductor nanospheres. Opt. Express 2013, 21, 23007-23020. [CrossRef]

33. Algorri, J.F.; García-Cámara, B.; García-García, A.; Urruchi, V.; Sánchez-Pena, J.M. Theoretical modeling of a Localized Surface Plasmon Resonance (LSPR) based fiber optic temperature sensor. In Proceedings of the OFS2014 23rd International Conference on Optical Fiber Sensors, Santander, Spain, 2-6 June 2014; p. 915738.

34. Zografopoulos, D.C.; Beccherelli, R. Plasmonic variable optical attenuator based on liquid-crystal tunable stripe waveguides. Plasmonics 2013, 8, 599-604. [CrossRef]

35. Zografopoulos, D.C.; Beccherelli, R. Long-range plasmonic directional coupler switches controlled by nematic liquid crystals. Opt. Express 2013, 21, 8240. [CrossRef]

36. Zografopoulos, D.C.; Beccherelli, R. Design of a vertically coupled liquid-crystal long-range plasmonic optical switch. Appl. Phys. Lett. 2013, 102, 101103. [CrossRef] 
37. He, S.; Liang, W.; Cheng, K.-L.; Fang, J.; Wu, S.-T. Bile acid-surfactant interactions at the liquid crystal/aqueous interface. Soft Matter 2014, 10, 4609-4614. [CrossRef]

38. Otón, E.; Otón, J.M.; Caño-García, M.; Escolano, J.M.; Quintana, X.; Geday, M.A. Rapid detection of pathogens using lyotropic liquid crystals. Opt. Express 2019, 27, 10098. [CrossRef]

39. Carrasco-Vela, C.; Quintana, X.; Otón, E.; Geday, M.A.; Otón, J.M. Security devices based on liquid crystals doped with a colour dye. Opto-Electron. Rev. 2011, 19, 496-500. [CrossRef]

40. Marcos, C.; Sánchez-Pena, J.M.; Torres, J.C.; Santos, J.I. Temperature-frequency converter using a liquid crystal cell as a sensing element. Sensors 2012, 12, 3204-3214. [CrossRef]

41. Algorri, J.F.; Zografopoulos, D.C.; Tapetado, A.; Poudereux, D.; Sánchez-Pena, J.M. Infiltrated photonic crystal fibers for sensing applications. Sensors 2018, 18, 4263. [CrossRef]

42. Li, J.; Gauza, S.; Wu, S.-T.; Alkeskjold, T.T.; Lægsgaard, J.; Bjarklev, A. High dn o/dT liquid crystals and their applications in a thermally tunable liquid crystal photonic crystal fiber. Mol. Cryst. Liq. Cryst. 2006, 453, 355-370. [CrossRef]

43. Jang, E. Electrooptic temperature sensor based on a Fabry-Pe/spl acute/rot resonator with a liquid crystal film. IEEE Photonics Technol. Lett. 2006, 18, 905-907.

44. Wang, Y.; Yang, M.; Wang, D.N.; Liao, C.R. Selectively infiltrated photonic crystal fiber with ultrahigh temperature sensitivity. IEEE Photonics Technol. Lett. 2011, 23, 1520-1522. [CrossRef]

45. Davies, D.J.D.; Vaccaro, A.R.; Morris, S.M.; Herzer, N.; Schenning, A.P.H.J.; Bastiaansen, C.W.M. A printable optical time-temperature integrator based on shape memory in a chiral nematic polymer network. Adv. Funct. Mater. 2013, 23, 2723-2727. [CrossRef]

46. Algorri, J.F.; Urruchi, V.; Bennis, N.; Sánchez-Pena, J.M. Liquid crystal temperature sensor based on a micrometric structure and a metallic nanometric layer. IEEE Electron Device Lett. 2014, 35, 666-668.

47. Algorri, J.F.; Urruchi, V.; Bennis, N.; Sánchez-Pena, J.M. A novel high-sensitivity, low-power, liquid crystal temperature sensor. Sensors 2014, 14, 6571-6883. [CrossRef]

48. Algorri, J.F.; Garcia-Camara, B.; Urruchi, V.; Sanchez-Pena, J.M. High-sensitivity fabry-pérot temperature sensor based on liquid crystal doped with nanoparticles. IEEE Photonics Technol. Lett. 2015, 27, $292-295$. [CrossRef]

49. Algorri, J.F.; Garcia-Camara, B.; Garcia-Garcia, A.; Urruchi, V.; Sánchez-Pena, J.M. Fiber optic temperature sensor based on amplitude modulation of metallic and semiconductor nanoparticles in a liquid crystal mixture. J. Light. Technol. 2015, 33, 2451-2455. [CrossRef]

50. Otón, J.M.; Otón, E.; Quintana, X.; Geday, M.A. Liquid-crystal phase-only devices. J. Mol. Liq. 2018, 267, 469-483. [CrossRef]

51. Bao-Guang, J.; Zhao-Liang, C.; Quan-Quan, M. Simulated human eye retina adaptive optics imaging system based on a liquid crystal on silicon device. Chin. Phys. B 2008, 17, 4529-4532. [CrossRef]

52. Valley, P.; Reza Dodge, M.; Schwiegerling, J.; Peyman, G.; Peyghambarian, N. Nonmechanical bifocal zoom telescope. Opt. Lett. 2010, 35, 2582-2584. [CrossRef]

53. Otón, E.; Carrasco, A.; Vergaz, R.; Otón, J.M.; Sánchez-Pena, J.M.; Quintana, X.; Geday, M. 2D tunable beam steering-lens device based on high birefringence liquid crystals. In Proceedings of the 2011 International Conference on Space Optical Systems and Applications (ICSOS), Santa Monica, CA, USA, 11-13 May 2011.

54. Kotova, S.P.; Patlan, V.V.; Samagin, S.A.; Zayakin, O.A. Wavefront formation using modal liquid-crystal correctors. Phys. Wave Phenom. 2010, 18, 96-104. [CrossRef]

55. Davies, R.; Kasper, M. Adaptive Optics for Astronomy. Annu. Rev. Astron. Astrophys. 2012, 50. [CrossRef]

56. Kao, Y.-Y.; Huang, Y.-P.; Yang, K.-X.; Chao, P.C.-P.; Tsai, C.-C.; Mo, C.-N. An auto-stereoscopic 3D display using tunable liquid crystal lens array that mimics effects of grin lenticular lens array. SID Symp. Dig. Tech. Pap. 2009, 40, 111-115. [CrossRef]

57. Algorri, J.F.; Urruchi del Pozo, V.; Sanchez-Pena, J.M.; Oton, J.M. An autostereoscopic device for mobile applications based on a liquid crystal microlens array and an OLED display. J. Disp. Technol. 2014, 10, 713-720. [CrossRef]

58. Algorri, J.F.; Urruchi, V.; Bennis, N.; Sánchez-Pena, J.M. Cylindrical liquid crystal microlens array with rotary axis and tunable capability. IEEE Electron Device Lett. 2015, 36, 582-584. [CrossRef]

59. Algorri, J.F.; Urruchi, V.; Bennis, N.; Morawiak, P.; Sanchez-Pena, J.M.; Oton, J.M. Integral imaging capture system with tunable field of view based on liquid crystal microlenses. IEEE Photonics Technol. Lett. 2016, 28, 1854-1857. [CrossRef] 
60. Algorri, J.F.; Urruchi, V.; Bennis, N.; Sánchez-Pena, J.M.; Otón, J.M. Tunable liquid crystal cylindrical micro-optical array for aberration compensation. Opt. Express 2015, 23, 13899-13915. [CrossRef] [PubMed]

61. Algorri, J.F.; Urruchi, V.; Bennis, N.; Sánchez-Pena, J.M. Modal liquid crystal microaxicon array. Opt. Lett. 2014, 39, 3476-3479. [CrossRef]

62. Algorri, J.F.; Love, G.D.; Urruchi, V. Modal liquid crystal array of optical elements. Opt. Express 2013, 21, 24809-24818. [CrossRef] [PubMed]

63. Algorri, J.F.; Bennis, N.; Urruchi, V.; Morawiak, P.; Sánchez-Pena, J.M.; Jaroszewicz, L.R. Tunable liquid crystal multifocal microlens array. Sci. Rep. 2017, 7, 17318. [CrossRef]

64. Algorri, J.F.; Urruchi, V.; Bennis, N.; Morawiak, P.; Sánchez-Pena, J.M.; Otón, J.M. Liquid crystal spherical microlens array with high fill factor and optical power. Opt. Express 2017, 25, 605. [CrossRef]

65. Algorri, J.F.; Bennis, N.; Herman, J.; Kula, P.; Urruchi, V.; Sánchez-Pena, J.M. Low aberration and fast switching microlenses based on a novel liquid crystal mixture. Opt. Express 2017, 25, 14795. [CrossRef] [PubMed]

66. Albero, J.; Garcia-Martinez, P.; Bennis, N.; Oton, E.; Cerrolaza, B.; Moreno, I.; Davis, J.A. Liquid crystal devices for the reconfigurable generation of optical vortices. J. Light. Technol. 2012, 30, 3055-3060. [CrossRef]

67. Algorri, J.F.; Urruchi, V.; Garcia-Camara, B.; Sanchez-Pena, J.M. Generation of optical vortices by an ideal liquid crystal spiral phase plate. IEEE Electron Device Lett. 2014, 35, 856-858. [CrossRef]

68. Caño-García, M.; Quintana, X.; Otón, J.M.; Geday, M.A. Dynamic multilevel spiral phase plate generator. Sci. Rep. 2018, 8, 15804. [CrossRef]

69. Kotova, S.P.; Mayorova, A.M.; Samagin, S.A. Formation of ring-shaped light fields with orbital angular momentum using a modal type liquid crystal spatial modulator. J. Opt. 2018, 20, 055604. [CrossRef]

70. Algorri, J.; Urruchi, V.; García-Cámara, B.; Sánchez-Pena, J. Liquid crystal lensacons, logarithmic and linear axicons. Materials 2014, 7, 2593-2604. [CrossRef] [PubMed]

71. Wu, S.-T.; Ren, H. Introduction to Adaptive Lenses; Wiley: Hoboken, NJ, USA, 2012; ISBN 9781118270080.

72. Alvarez, L.W. Two-element variable-power spherical lens. US Patent No. 3,305,294, 21 February 1967.

73. Alvarez, L.W. Development of variable- focus lenses and a new refractor. J. Am. Optom. Assoc. 1978, 49, 24-29. [PubMed]

74. Lohmann, A.W. A new class of varifocal lenses. Appl. Opt. 1970, 9, 1669. [CrossRef] [PubMed]

75. Barton, I.M.; Dixit, S.N.; Summers, L.J.; Thompson, C.A.; Avicola, K.; Wilhelmsen, J. Diffractive alvarez lens. Opt. Lett. 2000, 25, 1. [CrossRef]

76. Zhou, G.; Yu, H.; Chau, F.S. Microelectromechanically-driven miniature adaptive Alvarez lens. Opt. Express 2013, 21, 1226. [CrossRef] [PubMed]

77. Bawart, M.; Jesacher, A.; Zelger, P.; Bernet, S.; Ritsch-Marte, M. Modified Alvarez lens for high-speed focusing. Opt. Express 2017, 25, 29847. [CrossRef]

78. Schneider, F.; Draheim, J.; Kamberger, R.; Waibel, P.; Wallrabe, U. Optical characterization of adaptive fluidic silicone-membrane lenses. Opt. Express 2009, 17, 11813. [CrossRef]

79. Zhang, D.-Y.; Lien, V.; Berdichevsky, Y.; Choi, J.; Lo, Y.-H. Fluidic adaptive lens with high focal length tunability. Appl. Phys. Lett. 2003, 82, 3171-3172. [CrossRef]

80. Ren, H.; Fox, D.; Anderson, P.A.; Wu, B.; Wu, S.-T. Tunable-focus liquid lens controlled using a servo motor. Opt. Express 2006, 14, 8031. [CrossRef]

81. Sugiura, N.; Morita, S. Variable-focus liquid-filled optical lens. Appl. Opt. 1993, 32, 4181. [CrossRef]

82. Ren, H.; Wu, S.-T. Variable-focus liquid lens by changing aperture. Appl. Phys. Lett. 2005, 86, 211107. [CrossRef]

83. Hasan, N.; Banerjee, A.; Kim, H.; Mastrangelo, C.H. Tunable-focus lens for adaptive eyeglasses. Opt. Express 2017, 25, 1221. [CrossRef] [PubMed]

84. Xiao, W.; Hardt, S. An adaptive liquid microlens driven by a ferrofluidic transducer. J. Micromechanics Microengineering 2010, 20, 055032. [CrossRef]

85. Cheng, H.-C.; Xu, S.; Liu, Y.; Levi, S.; Wu, S.-T. Adaptive mechanical-wetting lens actuated by ferrofluids. Opt. Commun. 2011, 284, 2118-2121. [CrossRef]

86. Malouin Jr, B.A.; Vogel, M.J.; Olles, J.D.; Cheng, L.; Hirsa, A.H. Electromagnetic liquid pistons for capillarity-based pumping. Lab Chip 2011, 11, 393-397. [CrossRef]

87. Ren, H.; Wu, S.-T.; Ren, H.; Wu, S.-T. Adaptive lenses based on soft electroactive materials. Appl. Sci. 2018, 8, 1085. [CrossRef] 
88. Tabiryan, N.; Serak, S.; Dai, X.-M.; Bunning, T. Polymer film with optically controlled form and actuation. Opt. Express 2005, 13, 7442. [CrossRef] [PubMed]

89. Yu, Y.; Nakano, M.; Ikeda, T. Directed bending of a polymer film by light. Nature 2003, 425, 145. [CrossRef]

90. Xu, S.; Ren, H.; Lin, Y.-J.; Moharam, M.G.J.; Wu, S.-T.; Tabiryan, N. Adaptive liquid lens actuated by photo-polymer. Opt. Express 2009, 17, 17590. [CrossRef] [PubMed]

91. Dong, L.; Agarwal, A.K.; Beebe, D.J.; Jiang, H. Adaptive liquid microlenses activated by stimuli-responsive hydrogels. Nature 2006, 442, 551-554. [CrossRef]

92. Ehrick, J.D.; Stokes, S.; Bachas-Daunert, S.; Moschou, E.A.; Deo, S.K.; Bachas, L.G.; Daunert, S. Chemically tunable lensing of stimuli-responsive hydrogel microdomes. Adv. Mater. 2007, 19, 4024-4027. [CrossRef]

93. Das, T.K.; Prusty, S. Review on conducting polymers and their applications. Polym. Plast. Technol. Eng. 2012, 51, 1487-1500. [CrossRef]

94. Nemat-Nasser, S.; Wu, Y. Comparative experimental study of ionic polymer-metal composites with different backbone ionomers and in various cation forms. J. Appl. Phys. 2003, 93, 5255-5267. [CrossRef]

95. Baughman, R.H.; Cui, C.; Zakhidov, A.A.; Iqbal, Z.; Barisci, J.N.; Spinks, G.M.; Wallace, G.G.; Mazzoldi, A.; De Rossi, D.; Rinzler, A.G.; et al. Carbon nanotube actuators. Science 1999, 284, 1340-1344. [CrossRef]

96. Shian, S.; Diebold, R.M.; Clarke, D.R. Tunable lenses using transparent dielectric elastomer actuators. Opt. Express 2013, 21, 8669. [CrossRef]

97. Carpi, F.; Frediani, G.; Turco, S.; De Rossi, D. Bioinspired tunable lens with muscle-like electroactive elastomers. Adv. Funct. Mater. 2011, 21, 4152-4158. [CrossRef]

98. Ali, M.; Ueki, T.; Tsurumi, D.; Hirai, T. Influence of plasticizer content on the transition of electromechanical behavior of PVC gel actuator. Langmuir 2011, 27, 7902-7908. [CrossRef]

99. Xia, H.; Takasaki, M.; Hirai, T. Actuation mechanism of plasticized PVC by electric field. Sens. Actuators A Phys. 2010, 157, 307-312. [CrossRef]

100. Cheng, C.-C.; Andrew Yeh, J. Dielectrically actuated liquid lens. Opt. Express 2007, 15, 7140. [CrossRef] [PubMed]

101. Kim, Y.; Francl, J.; Taheri, B.; West, J.L. A method for the formation of polymer walls in liquid crystal/polymer mixtures. Appl. Phys. Lett. 1998, 72, 2253-2255. [CrossRef]

102. Berreman, D.W. Variable-focus LC-lens system. US Patent No. 4,190,330, 26 February 1980.

103. Sato, S. Liquid-crystal lens-cell with variable focal length. Jpn. J. Appl. Phys. 1979, 18, 1679-1684. [CrossRef]

104. Kowel, S.T.; Cleverly, D.S. A liquid crystal adaptive lens. In Proceedings of the NASA Conference on Optical Information Processing for Aerospace Applications, Hampton, VI, USA, 1981.

105. Cleverly, D. Creation of a Lens by Field Controlled Variation of the Index of Refraction in a Liquid Crystal. Ph.D. Thesis, Syracuse University, Syracuse, NY, USA, 1982.

106. Riza, N.A.; Dejule, M.C. Three-terminal adaptive nematic liquid-crystal lens device. Opt. Lett. 1994, 19, 1013-1015. [CrossRef]

107. Nose, T.; Sato, S. A liquid crystal microlens obtained with a non-uniform electric field. Liq. Cryst. 1989, 5, 1425-1433. [CrossRef]

108. Nose, T.; Sato, S. Optical properties of a liquid crystal microlens. In Proceedings of the International Conference on Optoelectronic Science and Engineering, Beijing, China, 22-25 August 1990; Volume 1230.

109. Williams, G.; Powell, N.; Purvis, A.; Clark, M.G. Electrically controllable liquid crystal fresnel lens. In Proceedings of the Opto-electronics Symposium SPIE 1168, San Diego, CA, USA, 7-11 August 1989.

110. Abramochkin, E.G.; Vasiliev, A.A.; Vashurin, P.V.; Zhmurova, L.I.; Ignatov, V.A.; Naumov, A.F. Controlled liquid crystal lens. Prepr. P. N. Lebedev Phys. Inst. 1988, 194, 18.

111. Naumov, A.F.; Loktev, M.Y.; Guralnik, I.R.; Vdovin, G.V. Liquid-crystal adaptive lenses with modal control. Opt. Lett. 1998, 23, 992-994. [CrossRef]

112. Love, G.D.; Naumov, A.F. Modal liquid crystal lenses. Liq. Cryst. Today 2000, 10, 1-4. [CrossRef]

113. Vdovin, G.V.; Guralnik, I.R.; Zayakin, O.A.; Klimov, N.A.; Kotova, S.P.; Loktev, M.Y.; Naumov, A.F.; Patlan, V.V.; Samagin, S.A. Modal liquid crystal wavefront corrector. Bull. Russ. Acad. Sci. 2008, 72, 71-77.

114. Kotova, S.P.; Patlan, V.V.; Samagin, S.A. Tunable liquid-crystal focusing device. 1. Theory. Quantum Electron. 2011, 41, 58-64. [CrossRef]

115. Kotova, S.P.; Patlan, V.V.; Samagin, S.A. Tunable liquid-crystal focusing device. $2 . \quad$ Experiment. Quantum Electron. 2011, 41, 65-70. [CrossRef] 
116. Hands, P.J.W.; Tatarkova, S.A.; Kirby, A.K.; Love, G.D. Modal liquid crystal devices in optical tweezing: 3D control and oscillating potential wells. Opt. Express 2006, 14, 4525. [CrossRef]

117. Korobtsov, A.; Kotova, S.; Losevsky, N.; Mayorova, A.; Samagin, S. Compact optical tweezer with the capability of dynamic control. J. Biomed. Photonics Eng. 2015, 1, 154-163. [CrossRef]

118. Flexible Optical B., V. LC Lenses. Available online: www.okotech.com/lc. (accessed on 24 May 2019).

119. Xu, S.; Li, Y.; Liu, Y.; Sun, J.; Ren, H.; Wu, S.-T.; Xu, S.; Li, Y.; Liu, Y.; Sun, J.; et al. Fast-response liquid crystal microlens. Micromachines 2014, 5, 300-324. [CrossRef]

120. Algorri, J.; Urruchi, V.; García-Cámara, B.; Sánchez-Pena, J.; Algorri, J.F.; Urruchi, V.; García-Cámara, B.; Sánchez-Pena, J.M. Liquid crystal microlenses for autostereoscopic displays. Materials 2016, 9, 36. [CrossRef] [PubMed]

121. Kim, S.-U.; Na, J.-H.; Kim, C.; Lee, S.-D. Design and fabrication of liquid crystal-based lenses. Liq. Cryst. 2017, 1-12. [CrossRef]

122. Bailey, J.; Morgan, P.; Gleeson, H.; Jones, J.; Bailey, J.; Morgan, P.B.; Gleeson, H.F.; Jones, J.C. Switchable liquid crystal contact lenses for the correction of presbyopia. Crystals 2018, 8, 29. [CrossRef]

123. Lin, Y.-H.; Wang, Y.-J.; Reshetnyak, V. Liquid crystal lenses with tunable focal length. Liq. Cryst. Rev. 2017, 5, 111-143. [CrossRef]

124. Ye, M.; Wang, B.; Uchida, M.; Yanase, S.; Takahashi, S.; Sato, S. Focus tuning by liquid crystal lens in imaging system. Appl. Opt. 2012, 51,7630-7635. [CrossRef]

125. Lin, Y.-H.; Chen, M.-S. A pico projection system with electrically tunable optical zoom ratio adopting two liquid crystal lenses. J. Disp. Technol. 2012, 8, 401-404. [CrossRef]

126. Lin, H.-C.; Collings, N.; Chen, M.-S.; Lin, Y.-H. A holographic projection system with an electrically tuning and continuously adjustable optical zoom. Opt. Express 2012, 20, 27222-27229. [CrossRef]

127. Tsou, Y.-S.; Chang, K.-H.; Lin, Y.-H. A droplet manipulation on a liquid crystal and polymer composite film as a concentrator and a sun tracker for a concentrating photovoltaic system. J. Appl. Phys. 2013, 113, 244504. [CrossRef]

128. Chen, M.; Chen, C.-H.; Lai, Y.; Lu, Y.; Lin, Y.-H. An electrically tunable polarizer for a fiber system based on a polarization-dependent beam size derived from a liquid crystal lens. IEEE Photonics J. 2014, 6, 1-8. [CrossRef]

129. Kawamura, M.; Ye, M.; Sato, S. Optical trapping and manipulation system using liquid-crystal lens with focusing and deflection properties. Jpn. J. Appl. Phys. 2005, 44, 6098-6100. [CrossRef]

130. Hassanfiroozi, A.; Huang, Y.-P.; Javidi, B.; Shieh, H.-P.D. Hexagonal liquid crystal lens array for 3D endoscopy. Opt. Express 2015, 23, 971-981. [CrossRef]

131. Wang, Y.-J.; Chen, P.-J.; Liang, X.; Lin, Y.-H. Augmented reality with image registration, vision correction and sunlight readability via liquid crystal devices. Sci. Rep. 2017, 7, 433. [CrossRef]

132. Li, G.; Mathine, D.L.; Valley, P.; Ayräs, P.; Haddock, J.N.; Giridhar, M.S.; Williby, G.; Schwiegerling, J.; Meredith, G.R.; Kippelen, B.; et al. Switchable electro-optic diffractive lens with high efficiency for ophthalmic applications. Proc. Natl. Acad. Sci. USA 2006, 103, 6100-6104. [CrossRef]

133. Peyghambarian, N.; Li, G. Liquid Crystal lenses for correction of presbyopia. In Adaptive Optics for Industry and Medicine; Christopher Dainty, Ed.; National University of Ireland: Dublin, Ireland, 2007; Volume 1, pp. 3-8.

134. Milton, H.E.; Morgan, P.B.; Clamp, J.H.; Gleeson, H.F. Electronic liquid crystal contact lenses for the correction of presbyopia. Opt. Express 2014, 22, 8035. [CrossRef] [PubMed]

135. Kaur, S.; Kim, Y.-J.; Milton, H.; Mistry, D.; Syed, I.M.; Bailey, J.; Novoselov, K.S.; Jones, J.C.; Morgan, P.B.; Clamp, J.; et al. Graphene electrodes for adaptive liquid crystal contact lenses. Opt. Express 2016, $24,8782$. [CrossRef]

136. Optics, P. Electronic Eyewear. Available online: www.pixeloptics.com/pages/electronic_eyewear. (accessed on 25 June 2015).

137. Lin, Y.-H.; Chen, H.-S. Electrically tunable-focusing and polarizer-free liquid crystal lenses for ophthalmic applications. Opt. Express 2013, 21, 9428-9436. [CrossRef]

138. Syed, I.M.; Kaur, S.; Milton, H.E.; Mistry, D.; Bailey, J.; Morgan, P.B.; Jones, J.C.; Gleeson, H.F. Novel switching mode in a vertically aligned liquid crystal contact lens. Opt. Express 2015, 23, 9911. [CrossRef] [PubMed]

139. Bailey, J.; Kaur, S.; Morgan, P.B.; Gleeson, H.F.; Clamp, J.H.; Jones, J.C. Design considerations for liquid crystal contact lenses. J. Phys. D Appl. Phys. 2017, 50, 485401. [CrossRef] 
140. Vanhaverbeke, C.; Verplancke, R.; De Smet, J.; Cuypers, D.; De Smet, H. Microfabrication of a spherically curved liquid crystal display enabling the integration in a smart contact lens. Displays 2017, 49, 16-25. [CrossRef]

141. Dou, H.; Chu, F.; Guo, Y.-Q.; Tian, L.-L.; Wang, Q.-H.; Sun, Y.-B. Large aperture liquid crystal lens array using a composited alignment layer. Opt. Express 2018, 26, 9254. [CrossRef]

142. Hsu, C.-J.; Jhang, J.-J.; Huang, C.-Y. Large aperture liquid crystal lens with an imbedded floating ring electrode. Opt. Express 2016, 24, 16722. [CrossRef]

143. Hsu, C.-J.; Jhang, J.-J.; Jhang, J.-C.; Huang, C.-Y. Influence of floating-ring-electrode on large-aperture liquid crystal lens. Liq. Cryst. 2018, 45, 40-48. [CrossRef]

144. Li, L.; Bryant, D.; Bos, P.J. Liquid crystal lens with concentric electrodes and inter-electrode resistors. Liq. Cryst. Rev. 2014, 2, 130-154. [CrossRef]

145. Beeckman, J.; Yang, T.-H.; Nys, I.; George, J.P.; Lin, T.-H.; Neyts, K. Multi-electrode tunable liquid crystal lenses with one lithography step. Opt. Lett. 2018, 43, 271. [CrossRef]

146. Naumov, A.F.; Love, G.D.; Loktev, M.Y.; Vladimirov, F.L. Control optimization of spherical modal liquid crystal lenses. Opt. Express 1999, 4, 344-352. [CrossRef]

147. Loktev, M.Y.; Belopukhov, V.N.; Vladimirov, F.L.; Vdovin, G.V.; Love, G.D.; Naumov, A.F. Wave front control systems based on modal liquid crystal lenses. Rev. Sci. Instrum. 2000, 71, 3290-3297. [CrossRef]

148. Kirby, A.K.; Hands, P.J.; Love, G.D. Liquid crystal multi-mode lenses and axicons based on electronic phase shift control. Opt. Express 2007, 15, 13496-13501. [CrossRef]

149. Fraval, N.; de Bougrenet, J.L. Low aberrations symmetrical adaptive modal liquid crystal lens with short focal lengths. Appl. Opt. 2010, 49, 2778-2783. [CrossRef] [PubMed]

150. Hassanfiroozi, A.; Huang, Y.-P.; Javidi, B.; Shieh, H.-P.D. Dual layer electrode liquid crystal lens for 2D/3D tunable endoscopy imaging system. Opt. Express 2016, 24, 8527. [CrossRef] [PubMed]

151. Ye, M.; Chen, X.; Li, Q.; Zeng, J.; Yu, S. Depth from defocus measurement method based on liquid crystal lens. Opt. Express 2018, 26, 28413. [CrossRef] [PubMed]

152. Li, H.; Peng, J.; Pan, F.; Wu, Y.; Zhang, Y.; Xie, X. Focal stack camera in all-in-focus imaging via an electrically tunable liquid crystal lens doped with multi-walled carbon nanotubes. Opt. Express 2018, 26, 12441. [CrossRef]

153. Galstian, T.; Asatryan, K.; Presniakov, V.; Zohrabyan, A.; Tork, A.; Bagramyan, A.; Careau, S.; Thiboutot, M.; Cotovanu, M. High optical quality electrically variable liquid crystal lens using an additional floating electrode. Opt. Lett. 2016, 41, 3265. [CrossRef] [PubMed]

154. Galstian, T.; Sova, O.; Asatryan, K.; Presniakov, V.; Zohrabyan, A.; Evensen, M. Optical camera with liquid crystal autofocus lens. Opt. Express 2017, 25, 29945. [CrossRef] [PubMed]

155. Sova, O.; Galstian, T. Liquid crystal lens with optimized wavefront across the entire clear aperture. Opt. Commun. 2019, 433, 290-296. [CrossRef]

156. Chigrinov, V.; Chigrinov, G.V. Photoaligning and photopatterning-A new challenge in liquid crystal photonics. Crystals 2013, 3, 149-162. [CrossRef]

157. Sergan, T.A.; Sergan, V.; Herrera, R.; Lu, L.; Bos, P.J.; Sergan, E.V. In situ control of surface molecular order in liquid crystals using a localised polymer network and its application to electro-optical devices. Liq. Cryst. 2013, 40, 72-82. [CrossRef]

158. Sergan, V.V.; Sergan, T.A.; Bos, P.J. Control of the molecular pretilt angle in liquid crystal devices by using a low-density localized polymer network. Chem. Phys. Lett. 2010, 486, 123-125. [CrossRef]

159. Bezruchenko, V.S.; Muravsky, A.A.; Murauski, A.A.; Stankevich, A.I.; Mahilny, U.V. Tunable liquid crystal lens based on pretilt angle gradient alignment. Mol. Cryst. Liq. Cryst. 2016, 626, 222-228. [CrossRef]

160. Bezruchenko, V.S.; Mahilny, U.V.; Stankevich, A.I.; Muravsky, A.A.; Murauski, A.A. New photo-crosslinkable benzaldehyde polymers for creating liquid crystal lenses. J. Appl. Spectrosc. 2018, 85, 704-709. [CrossRef]

161. Kim, J.; Li, Y.; Miskiewicz, M.N.; Oh, C.; Kudenov, M.W.; Escuti, M.J. Fabrication of ideal geometric-phase holograms with arbitrary wavefronts. Optica 2015, 2, 958. [CrossRef]

162. Lee, Y.-H.; Tan, G.; Zhan, T.; Weng, Y.; Liu, G.; Gou, F.; Peng, F.; Tabiryan, N.V.; Gauza, S.; Wu, S.-T. Recent progress in Pancharatnam-Berry phase optical elements and the applications for virtual/augmented realities. Opt. Data Process. Storage 2017, 3, 79-88. [CrossRef]

163. Ma, Y.; Tam, A.M.W.; Gan, X.T.; Shi, L.Y.; Srivastava, A.K.; Chigrinov, V.G.; Kwok, H.S.; Zhao, J.L. Fast switching ferroelectric liquid crystal Pancharatnam-Berry lens. Opt. Express 2019, 27, 10079. [CrossRef] 
164. Zhan, T.; Lee, Y.-H.; Tan, G.; Xiong, J.; Yin, K.; Gou, F.; Zou, J.; Zhang, N.; Zhao, D.; Yang, J.; et al. Pancharatnam-Berry optical elements for head-up and near-eye displays. J. Opt. Soc. Am. B 2019, 36, D52. [CrossRef]

165. Moon, S.; Lee, C.-K.; Nam, S.-W.; Jang, C.; Lee, G.-Y.; Seo, W.; Sung, G.; Lee, H.-S.; Lee, B. Augmented reality near-eye display using Pancharatnam-Berry phase lenses. Sci. Rep. 2019, 9, 6616. [CrossRef] [PubMed]

166. Zhou, Y.; Yin, Y.; Yuan, Y.; Lin, T.; Huang, H.; Yao, L.; Wang, X.; Tam, A.M.W.; Fan, F.; Wen, S. Liquid crystal Pancharatnam-Berry phase lens with spatially separated focuses. Liq. Cryst. 2018, 1-6. [CrossRef]

167. Jamali, A.; Bryant, D.; Zhang, Y.; Grunnet-Jepsen, A.; Bhowmik, A.; Bos, P.J. Design of a large aperture tunable refractive Fresnel liquid crystal lens. Appl. Opt. 2018, 57, B10. [CrossRef]

168. Srivastava, A.K.; Wang, X.Q.; Gong, S.Q.; Shen, D.; Lu, Y.Q.; Chigrinov, V.G.; Kwok, H.S. Micro-patterned photo-aligned ferroelectric liquid crystal Fresnel zone lens. Opt. Lett. 2015, 40, 1643. [CrossRef] [PubMed]

169. Kumar, M.B.; Kang, D.; Jung, J.; Park, H.; Hahn, J.; Choi, M.; Bae, J.-H.; Kim, H.; Park, J. Ultrathin, polarization-independent, and focus-tunable liquid crystal diffractive lens for augmented reality. arXiv 2019, arXiv:1902.10889.

170. Wei, X.; Zheng, J.; Wang, Y.; Gao, Z.; Sun, L.; Lu, Y.; Zhuang, S. Multi-imaging characteristics of electrically controlled on-axis holographic polymer-dispersed liquid-crystal Fresnel lens. Opt. Eng. 2015, 54, 037110. [CrossRef]

171. Lin, S.-H.; Li, C.-Y.; Kuo, C.-T.; Yeh, H.-C. Fresnel lenses in $90^{\circ}$ twisted-nematic liquid crystals with optical and electrical controllability. IEEE Photonics Technol. Lett. 2016, 28, 1462-1464. [CrossRef]

172. Lin, S.-H.; Huang, B.-Y.; Li, C.-Y.; Yu, K.-Y.; Chen, J.-L.; Kuo, C.-T. Electrically and optically tunable Fresnel lens in a liquid crystal cell with a rewritable photoconductive layer. Opt. Mater. Express 2016, 6, 2229. [CrossRef]

173. Noda, K.; Momosaki, R.; Kawai, K.; Sakamoto, M.; Sasaki, T.; Kawatsuki, N.; Goto, K.; Ono, H. Trifocal lens system with liquid crystal Fresnel lens. Jpn. J. Appl. Phys. 2018, 57, 102502. [CrossRef]

174. Wang, X.-Q.; Yang, W.-Q.; Liu, Z.; Duan, W.; Hu, W.; Zheng, Z.-G.; Shen, D.; Chigrinov, V.G.; Kwok, H.-S. Switchable Fresnel lens based on hybrid photo-aligned dual frequency nematic liquid crystal. Opt. Mater. Express 2017, 7, 8. [CrossRef]

175. Avci, N.; Lee, Y.-H.; Hwang, S.-J. Switchable polarisation-independent blue phase liquid crystal Fresnel lens based on phase-separated composite films. Liq. Cryst. 2017, 44, 1078-1085. [CrossRef]

176. Lin, H.-Y.; Avci, N.; Hwang, S.-J. High-diffraction-efficiency Fresnel lens based on annealed blue-phase liquid crystal-polymer composite. Liq. Cryst. 2019, 1-8. [CrossRef]

177. Rong, N.; Li, Y.; Li, X.; Zhou, P.; Liu, S.; Lu, J.; Su, Y. Polymer-stabilized blue-phase liquid crystal fresnel lens cured with patterned light using a spatial light modulator. J. Disp. Technol. 2016, 12, 1008-1012. [CrossRef]

178. Dou, H.; Chu, F.; Wang, L.; Tian, L.-L.; Li, R.; Hou, W.-Y.; Wang, Q.-H. A polarisation-free blue phase liquid crystal lens with enhanced tunable focal length range. Liq. Cryst. 2018, 1-7. [CrossRef]

179. Chen, H.-S.; Wang, Y.-J.; Chang, C.-M.; Lin, Y.-H. A polarizer-free liquid crystal lens exploiting an embedded-multilayered structure. IEEE Photonics Technol. Lett. 2015, 27, 899-902. [CrossRef]

180. Zhan, T.; Xiong, J.; Lee, Y.-H.; Wu, S.-T. Polarization-independent Pancharatnam-Berry phase lens system. Opt. Express 2018, 26, 35026. [CrossRef] [PubMed]

(C) 2019 by the authors. Licensee MDPI, Basel, Switzerland. This article is an open access article distributed under the terms and conditions of the Creative Commons Attribution (CC BY) license (http://creativecommons.org/licenses/by/4.0/). 